\title{
Qualidade tecnológica da pluma do algodoeiro herbáceo cultivado com biossólidos
}

Juarez P. Pedroza ${ }^{1}$, Adrianus C. van Haandel ${ }^{2}$, Napoleão E. de M. Beltrão ${ }^{3}$, Jair A. Dionísio ${ }^{4}$ \& Maria E. M. Duarte ${ }^{1}$

\section{RESUMO}

Em condições de casa de vegetação do Centro Nacional de Pesquisa do algodão (Embrapa/CNPA), estudaram-se os efeitos de doses crescentes de lodo de esgoto, caleado a 50\% ST - biossólido (equivalentes a 0,60, 100, 200, 250 e $300 \mathrm{~kg} \mathrm{~N} \mathrm{ha}^{-1}$ ), sobre a qualidade tecnológica da pluma (finura, resistência, comprimento, uniformidade de comprimento, índice de fibra curta, elongação, fiabilidade, reflectância e grau de amarelo) do algodoeiro herbáceo, variedade BRS $1878 \mathrm{H}$. O delineamento experimental utilizado foi em blocos ao acaso, com 6 tratamentos e 5 repetições, totalizando 30 unidades experimentais. Cada unidade experimental se constitui de vaso plástico de $90 \mathrm{dm}^{3}$ que receberam $70 \mathrm{dm}^{3}$ de solo. Com os resultados obtidos, verificou-se efeito significativo das doses de biossólido sobre as variáveis estudadas. Com o desdobramento da análise de regressão, verificou-se um ajuste quadrático dessas variáveis em função das doses de biossólido. A derivação das equações de regressão estimou que as doses de biossólidos entre 220 e $335 \mathrm{~kg} \mathrm{~N}^{-1}$ proporcionaram o valor máximo para as variáveis de interesse. A dose de biossólido equivalente a $292 \mathrm{~kg} \mathrm{~N} \mathrm{ha}^{-1}$ foi a que proporcionou o valor máximo para a variável resistência de fibra, que é tomada como base de compra do algodão.

Palavras-chave: lodo de esgoto, fibra, Cossypium hirsutum L.

\section{Technological fiber quality of herbaceous cotton cultivated with biosolids}

\begin{abstract}
Under greenhouse conditions at National Center for Research on Cotton (CNPA/ Embrapa), the effects of increasing doses of sewage sludge limited to $50 \%$ of dryness (equivalent to $0,60,100,200,250$ and $300 \mathrm{~kg} \mathrm{~N} \mathrm{ha}^{-1}$ ) were studied on the fiber quality (finess or micronaire, strength, length, length uniformity, short fiber index, elongation, stretching, spinning capability, reflectiveness and color grade) of herbaceous cotton variety BRS $1878 \mathrm{H}$. The experimental design adopted was a randomized blocks, with six treatments and five replications, resulting in 30 experimental units. Each experimental unit was composed of $90 \mathrm{dm}^{3}$ plastic pot with $70 \mathrm{dm}^{3}$ of soil. Significant quadratic effects were obtained with solid sewage sludge doses on the studied variables. The regression analyses estimated the dose of biosolids between 220 to $335 \mathrm{~kg} \mathrm{~N} \mathrm{ha}^{-1}$ for the maximum values of the variables of interest. For maximum fiber resistance value, which is used as base for commercialization of cotton, the dose of biosolid was equivalent to $292 \mathrm{~kg} \mathrm{ha}^{-1}$ of $\mathrm{N}$.
\end{abstract}

Key words: sewage sludge, fiber, Gossypium hirsutum L.

1 UAEAg//UFCG. Av. Aprígio Veloso 882, Bodocongó, CEP 58109-970, Campina Grande, PB. Fone: (83) 310-1550. E-mail: juarez@deag.ufcg.edu.br ${ }^{2}$ UAEC/UFCG. Fone: (83) 3331-4809. E-mail: prosab@uol.com.br

3 Pesquisador da EMBRAPA Algodão, Rua Osvaldo Cruz 1143, CEP 58107-720, Campina Grande, PB, E-mail: nbeltrao@cnpa.embrapa.br

${ }^{4}$ DSEA/UFPR, Rua dos Funcionários 1540, CEP 80035-050. Curitiba/PR, E-mail: jair@agrarias.ufpr.br. Fone: (41) 30296937 


\section{INTRODUÇÃO}

A contaminação de corpos hídricos com matéria orgânica tem origem principalmente nos esgotos domésticos e em águas residuárias das agroindústrias. Para que o esgoto não cause problemas ambientais e de saúde pública, é necessário que seja tratado antes do lançamento nos corpos receptores (rios, lagos, oceanos e solo). Esses tratamentos atuam de duas formas: na redução do conteúdo da matéria orgânica, por meio de sua oxidação, e no estímulo à formação de flocos, de forma a possibilitar a sedimentação e a remoção de um subproduto (resíduo) denominado lodo de esgoto ou biossólido, que possui as seguintes características indesejáveis: odores desagradáveis, presença de microrganismos patogênicos, elementos tóxicos de origem orgânica ou mineral e dificuldade de desidratação.

Seguindo as tendências do crescimento dos índices de coleta e tratamento de esgotos, ocorrerá um crescimento proporcional de produção de lodo, cuja disposição final tem sido um problema para a maioria das Estações de Tratamentos de Esgotos (ETE’s) que não dispõem de uma alternativa consistente para o destino final deste resíduo.

As principais alternativas de disposição final do lodo são os aterros sanitários, a disposição oceânica, a incineração e a reciclagem agrícola. Os aterros sanitários, além de possuírem o inconveniente de concorrer com os resíduos sólidos urbanos, apresentam altos custos de manutenção. A disposição oceânica, segundo Tsutiya (1999a), foi proibida nos Estados Unidos desde 1992, pela Ocean Dupimg Act, na Comunidade Européia desde 1998 e em vários países. A incineração, para evitar problemas de emissões atmosféricas, tem de usar incineradores de leito fluidizado, de custos elevados, além de demandar grande quantidade de energia. A reciclagem agrícola, segundo Andreoli et al. (1994) e Tsutiya (1999a), é a forma de disposição final que pode ser considerada mais adequada em termos técnicos, econômicos e ambientais, desde que convenientemente aplicada.

A destinação do lodo de esgoto para a agricultura é a alternativa que merece maior destaque, pelas seguintes razões, segundo Oliveira (2000): pode ser viabilizada tecnicamente pela pesquisa, apresenta os menores custos, utiliza o solo como meio favorável ao consumo da carga orgânica potencialmente poluidora, pode trazer os benefícios inerentes da matéria orgânica, além de proporcionar a reciclagem de nutrientes.

Dentre as alternativas de disposição final do lodo de esgoto, a reciclagem agrícola se tem constituído, de acordo com Neiva (1999), em uma das formas mais utilizadas em diversos países desenvolvidos (Bélgica, 29\%; Dinamarca, 54\%; França, 58\%; Alemanha, 27\%; Itália, 33\%; Espanha, 50\%; Reino Unido, 44\%) como condicionador e fertilizante do solo. Este resíduo, por sua vez, é fonte de matéria orgânica e de nutrientes para as plantas (Ros et al., 1991) e age como cor- retivo da acidez do solo (Berton et al., 1989; Dias, 1994).

Conforme Tsutiya (1999b) a reciclagem agrícola se constitui na alternativa mais adequada para a disposição final de biossólidos gerados nas ETE's do Estado de São Paulo.

Uma das alternativas para o uso de biossólido na agricultura seria no algodoeiro herbáceo, devido à sua importância na economia do Nordeste, uma vez que apresenta significativa contribuição para o produto interno bruto do País e para o emprego da mão-de-obra rural.

Considerando-se a inexistência, no Brasil, de trabalhos em que se estudem o uso de lodo de esgoto e seus efeitos nas variáveis relacionadas à qualidade tecnológica da pluma do algodoeiro, cujo produto principal é a fibra para a indústria têxtil, a importância do algodão na agricultura brasileira e o interesse agronômico de se dispor de uma fonte de matéria orgânica de tecnologia simples, barata, que contribuirá para a resolução ambientalmente segura de um problema que tende a se agravar, a medida em que são implantados e/ou ampliados os sistemas de coleta e tratamento de esgotos do país, este trabalho visa avaliar os efeitos de doses crescentes de biossólidos sobre a qualidade física de fibra do algodoeiro herbáceo (Gossypium hirsutum L r latifolium Hutch L).

\section{MATERIAL E MÉTODOS}

As etapas de obtenção, caracterização e desinfecção do lodo de esgoto (biossólido) foram realizadas nas instalações do Programa de Saneamento Básico (PROSAB) do Centro de Tecnologia e Recursos Naturais (CTRN) da Universidade Federal de Campina Grande (UFCG), enquanto o cultivo do algodoeiro o foi em condições de casa-de-vegetação do Centro Nacional de Pesquisa do Algodão (CNPA/EMBRAPA), também em Campina Grande, PB. Usou-se, como substrato para a condução do experimento, o Neossolo Regolítico (EMBRAPA, 1999), um solo típico da região do compartimento da Borborema, coletado próximo ao Município de Lagoa Seca, PB.

O lodo de esgoto, proveniente de Digestores Anaeróbio de Fluxo Ascendente (DAFA) e de Digestores Aeróbios, foi obtido no PROSAB - Campina Grande, PB. Antes de sua caracterização, o material foi colocado em tonéis dotados de drenos (camada de brita e de areia e tela) por onde foi percolado o excesso de água, até adquirir consistência pastosa.

Para a realização das análises físicas e químicas no lodo digerido (não desinfectado), o material foi secado ao ar e os resultados obtidos (Tabela 1 ), média de 3 repetições, estão expressos em relação à porcentagem de matéria seca, a $105 \pm 1{ }^{\circ} \mathrm{C}$. Tais análises foram realizadas segundo metodologia proposta pela Standard Methods for Examination of Water and Wastewater (AWWA, 1992).

Tabela 1. Composição física e química parcial do lodo de esgoto digerido*

\begin{tabular}{|c|c|c|c|c|c|c|c|c|c|}
\hline Composicão & $\begin{array}{c}\text { Sólido Total } \\
(\%)\end{array}$ & $\begin{array}{l}\text { Umidade } \\
(\%)\end{array}$ & $\underset{\mathrm{H}_{2} \mathrm{O}}{\mathrm{pH}}$ & $\begin{array}{l}\text { M. } 0 . \\
(\%)\end{array}$ & $\begin{array}{c}N \\
(\%)\end{array}$ & $\begin{array}{c}P \\
(\%)\end{array}$ & $\begin{array}{c}K \\
(\%)\end{array}$ & $\begin{array}{l}\mathrm{Ca} \\
(\%)\end{array}$ & $\begin{array}{l}\mathrm{Mg} \\
(\%)\end{array}$ \\
\hline & 12,26 & 87,54 & 6,7 & 49,66 & 4,13 & 2,28 & 0,46 & 1,44 & 2,03 \\
\hline
\end{tabular}

*Análises realizadas no Laboratório de Análises Químicas, Fisicas e Microbiológicas do PROSAB UAEC/CCT/UFCG, Campina Grande, PB 
Tabela 2. Principais características físicas de fibra do algodoeiro herbáceo, variedade BRS 187 8H, frente às demais linhagens. EMBRAPA Algodão, Campina Grande, PB

\begin{tabular}{lrc}
\hline \multicolumn{1}{c}{ Característica } & BRS 187 8H & Demais Linhagens (média) \\
Porcentagem média de fibra (\%) & 38,6 & 38,9 \\
Comprimento S. L. 2,5\% (mm) & 28,0 & 28,5 \\
Uniformidade de comprimento (\%) & 50,5 & 49,5 \\
Resistência (HV) (gf tex ${ }^{-1}$ ) & 20,8 & 20,5 \\
Finura (micronaire) & 4,5 & 4,1 \\
Alongamento (\%) & 7,0 & 7,0 \\
Reflectância & 61,0 & 61,8 \\
Grau de amarelo & 9,9 & 9,7 \\
\hline Fonte: CNPA (2000) & &
\end{tabular}

Por se tratar de uma variedade adequada para uso sequeiro no semi-árido nordestino, empregou-se como planta teste, o algodoeiro herbáceo, BRS 187 8H, cuja pluma tem as características apresentadas na Tabela 2.

A água de irrigação utilizada nas unidades experimentais foi a água de abastecimento da cidade de Campina Grande, PB.

Para eliminação dos patógenos e maus odores fez-se a caleação do lodo digerido com cal virgem (óxido de cálcio CaO), obtida no PROSAB, Campina Grande, PB, a 50\% da matéria seca (sólidos totais), uma vez que Gaspard (1996) e Ilhenfeld et al. (1999) encontraram o maior potencial de redução de ovos de helmintos, usando esta concentração de cal; tomaram-se por referência ovos de helmintos por serem, dentre os organismos patogênicos presentes em lodo de esgoto, reconhecidamente os mais disseminados e resistentes.

A caleação foi realizada em vasos plásticos de polietileno, com capacidade para $8 \mathrm{dm}^{3}$, contendo $2 \mathrm{dm}^{3}$ de lodo de esgoto. A aplicação das doses de cal ocorreu na superfície do lodo e, com auxílio de uma espátula, produziu-se uma mistura homogênea. Os vasos foram cobertos com filme plástico de polietileno e fechados hermeticamente com barbantes, para evitar perdas de umidade e amônia, respectivamente, por evaporação e volatilização e também, evitar contaminação de coliformes fecais.

Para garantir o manuseio e o uso agronômico seguros, coletaram-se amostras simples (nos intervalos de 2 h, 15 e 40 dias, após a caleação) em todos os vasos, de aproximadamente 250 g, para novas análises químicas e físicas, além de uma análise microbiológica (bacterológica) e outra parasitológica (ovos de helmintos), do lodo de esgoto desinfectado (biossólido).

As análises físicas e químicas no biossólido foram feitas pela mesma metodologia usada na caracterização do lodo de esgoto digerido, já descrita. As análises bacterológicas, realizadas por meio da contagem de Coliforme Fecais (CF), Estreptococos fecais (EF), Salmonella (S) e Clostridium perfrigens (CP), foram realizadas pela técnica de Tubos Múlti- plos, recomendada na Standard Methods for Examination of Water and Wastewater para lodos (AWWA, 1992), e as análises parasitológicas, realizadas por meio da quantificação de ovos de helmintos e da sua viabilidade, segundo a metodologia de Yanko, reconhecida pela USEPA (1992) como técnica oficial para os Estados Unidos. A caleação, a 50\% Sólidos Totais (ST), mostrou-se eficiente enquanto método de higienização do lodo de esgoto, uma vez que, tanto as bactérias indicadoras de contaminação fecal como os ovos de helmintos, foram eliminados pelo processo.

Encontram-se, na Tabela 3, as principais características físicas e químicas do biossólido, 40 dias após a caleação.

Foram quantificadas no solo, no lodo digerido e no biossólido, por espectrofotometria de absorção atômica, as concentrações totais de metais pesados, conforme metodologia proposta pela AWWA (1992). Os valores encontrados estão expressos na Tabela 4.

Tabela 4. Teores de metais pesados $\left(\mathrm{mg} \mathrm{kg}^{-1}\right)$ no solo, no lodo digerido e no biossólido usados no experimento*

\begin{tabular}{|c|c|c|c|c|c|c|c|c|}
\hline Material/Metal & B & Cd & Co & $\mathrm{Cr}$ & $\mathrm{Cu}$ & $\mathrm{Hg}$ & $\mathrm{Mg}$ & $\mathrm{Pb}$ \\
\hline Solo & $<200$ & $<0,48$ & $<2,5$ & 1,5 & 0,6 & $<0,1$ & 108 & $<8,4$ \\
\hline Lodo digerido & $<200$ & 1,2 & $<12$ & 112 & 162 & 0,6 & 3606 & 84 \\
\hline Biossólido & $<200$ & 0,71 & $<18$ & 26 & 0,4 & 0,9 & 46 & 37 \\
\hline
\end{tabular}

Os valores dos teores de metais pesados nos três materiais analisados estão muito aquém da concentração máxima permissível encontrada na literatura para uso agrícola. As baixas concentrações encontradas no lodo de esgoto do PROSAB, Campina Grande, podem ser explicadas pelo pequeno parque industrial existente nesta cidade sendo o esgoto gerado, por conseguinte, predominantemente doméstico.

A quantidade de biossólido em cada tratamento foi estimada em função do teor de nitrogênio total $(\mathrm{N})$ presente em $100 \mathrm{~g}$ de ST e a quantidade a ser mineralizada no ciclo da cultura. Os tratamentos empregados foram:

$\mathrm{T}_{1}$ - Testemunha (Solo nas condições naturais)

$\mathrm{T}_{2}$ - Solo $+60 \mathrm{~kg} \mathrm{~N} \mathrm{ha}^{-1}$ (equivalente a $2 \mathrm{t} \mathrm{ha}^{-1}$ de biossólido)

$\mathrm{T}_{3}$ - Solo $+100 \mathrm{~kg} \mathrm{~N} \mathrm{ha}^{-1}$ (equivalente a $4 \mathrm{t} \mathrm{ha}^{-1}$ de biossólido)

$\mathrm{T}_{4}-$ Solo $+200 \mathrm{~kg} \mathrm{~N}$ ha-1 $^{-1}$ (equivalente a $8 \mathrm{t} \mathrm{ha}^{-1}$ de biossólido)

$\mathrm{T}_{5}-$ Solo $+250 \mathrm{~kg} \mathrm{~N} \mathrm{ha}^{-1}$ (equivalente a $10 \mathrm{t} \mathrm{ha}^{-1}$ de biossólido)

$\mathrm{T}_{6}-$ Solo $+300 \mathrm{~kg} \mathrm{~N} \mathrm{ha}^{-1}$ (equivalente a $12 \mathrm{t} \mathrm{ha}^{-1}$ de biossólido)

No fundo de cada unidade experimental $\left(90 \mathrm{dm}^{3}\right.$ de capacidade), que recebeu aproximadamente $70 \mathrm{dm}^{3}$ de solo

Tabela 3. Composição física e química do biossólido após 40 dias da caleação a 50\% ST

\begin{tabular}{|c|c|c|c|c|c|c|c|c|c|}
\hline Composição & $\begin{array}{l}\text { Sólido Total } \\
\text { (\%) }\end{array}$ & $\begin{array}{c}\text { Umidade } \\
(\%)\end{array}$ & $\begin{array}{l}\mathrm{pH} \\
\mathrm{H}_{2} \mathrm{O}\end{array}$ & $\begin{array}{l}\text { M. } 0 . \\
(\%)\end{array}$ & $\begin{array}{l}\mathrm{N} \\
(\%)\end{array}$ & $\begin{array}{l}P \\
(\%)\end{array}$ & $\begin{array}{c}K \\
(\%)\end{array}$ & $\begin{array}{l}\mathrm{Ca} \\
(\%)\end{array}$ & $\begin{array}{l}\mathrm{Mg} \\
(\%)\end{array}$ \\
\hline & 22,7 & 77,3 & 12,5 & 33,4 & 2,6 & 1,5 & 0,3 & 20,3 & 3,1 \\
\hline
\end{tabular}

Análises realizadas no Laboratório de Análises Químicas, Físicas e Microbiológicas do PROSAB DEC/CTRN/UFCG, Campina. Grande, PB 
(coletado da camada superficial: 0-30 cm), foram feitos dois furos em extremidades opostas, que foram preenchidos com mangueiras (diâmetro $=0,5 \mathrm{~cm}$ ) por onde foi drenado o excesso de água. A água adicionada (água de abastecimento) em cada unidade experimental durante a condução do experimento, correspondia aproximadamente à capacidade de campo do solo utilizado.

Antes da semeadura as sementes foram previamente tratadas com fungicida sistêmico do grupo químico Benzimidazol (nome comercial Benomyl 500) para combater fungos fitopatogênicos do solo; cada unidade experimental recebeu 8 sementes e, quinze dias após a semeadura, realizou-se o desbaste, deixando-se duas plantas por vaso, que foram conduzidas até o final do ciclo fenológico da cultura (135 dias).

A cada 30 dias foram feitas aplicações de inseticida e acaricida sistêmico e de contato organofosforado do grupo químico Monocrotophos (nome comercial Agrophos 400) na dosagem de $6 \mathrm{~mL} \mathrm{~L}^{-1} \mathrm{H}_{2} \mathrm{O}$, para prevenir o ataque de mosca-branca e do pulgão do algodoeiro.

Durante a condução do experimento realizaram-se análises parasitológicas (ovos de helmintos) da água drenada no fundo de cada unidade experimental, a cada 30 dias, conforme metodologias da USEPA (1992) e Bailenger (1979).

As análises da qualidade física da fibra do algodão foram efetuadas pelo Instrumento de Alto Volume (HVI-Higth Volume Instruments), modelo 900, de Spinlab/Zellweger Uster, instalado no Laboratório de Fibras e Fios da Embrapa/CNPA, Campina Grande, PB; através deste instrumento, determinaram-se as seguintes características tecnológicas da pluma: finura (micronaire), em $\mu$ g, resistência, em gf tex ${ }^{-1}$ (a unidade métrica da resistência é o tex, que equivalea 9 denier, cuja unidade equivale à massa de $1 \mathrm{~g}$ por $9 \mathrm{~km}$ de fio), comprimento, em mm 2,5\% S.L., uniformidade de comprimento, em \%, índice de fibra curta (IFC), em \%, elongação, em \%, fiabilidade (CSP), reflectância, em \%, e grau de amarelo (+b).

Obedecendo a norma internacional ISO 139/ASTM D 1776/ NBR 8428-84 para análise de fibras, as amostras permaneceram 24 h no Laboratório, a temperatura de $20 \pm 1^{\circ} \mathrm{C}$ e umidade relativa de $65 \pm 2 \%$, para atingir o equilíbrio higrométrico (aclimatização).

O delineamento experimental adotado para os experimentos foi o de blocos ao acaso, com 6 tratamentos e 5 repetições, totalizando 30 unidades experimentais. O programa estatístico utilizado, para as análises de variância e de regressão, foi o SAS e o teste $\mathrm{F}$ foi o utilizado para as médias dos tratamentos.

\section{RESULTADOS E DISCUSSÃO}

Na Tabela 5 encontram-se os valores médios das variáveis relacionadas com a qualidade física de fibra do algodão, para os diferentes tratamentos testados e, na Tabela 6, tem-se o resumo das análises de variância e de regressão dessas variáveis.

As variáveis da qualidade física de fibra do algodão para a testemunha $\left(\mathrm{T}_{1}\right)$ não foram avaliadas, uma vez que a quantidade de pluma produzida nesse tratamento foi insuficiente para leitura no instrumento de alto volume (HVI).

Quando se compara com as características da qualidade física de fibra da cultivar BRS 187 8H (Tabela 2) verificou-se que os valores apresentados na Tabela 5 foram superiores, com exceção das variáveis, finura e grau de amarelo. O valor médio da finura foi de $3,70 \mathrm{mg}$, valor este que classifica a fibra do algodão na categoria fina que, em geral, produzem fios mais resistentes (devido ao maior número de fibras na seção do fio) mas, de acordo com Santana \& Wanderley (1995) e Santana (2002), produzem fios com maiores problemas de afinidade tintorial e com maior quantidade de neps; as fibras finas produzem fios mais uniformes com relação à ruptura na fiação; o ideal é que as fibras não sejam muito finas, nem muito grossas. Observase, ainda, na mesma Tabela, que o valor médio para a resistência foi de 28,77 gf tex ${ }^{-1}$, classificando a fibra na categoria média; o comprimento de 29,74 mm 2,5\% S.L. a classifica na categoria longa e a uniformidade de comprimento de $84,90 \%$ a classifica na categoria uniforme; o índice de fibra curta de 5,2\%; por ser inferior a 6,0\%, é classificado na categoria muito baixo, o que é salutar pois, quanto menor for este índice, melhor será a qualidade tecnológica da fibra. A elongação de 10,23\% e classificada como muito alta, tendo em vista que o seu valor é superior a 7,6\%. A fiabilidade de 2218 é classificada na categoria média, enquanto a reflectância de 71,10 é considerada alta e, por fim, o grau de amarelo de 9,14, está dentro da faixa normalmente encontrada, ou seja, entre 4 e 18 (Santana \& Wanderley, 1995; Santana, 2002).

Tabela 5. Médias dos tratamentos das variáveis da qualidade física da fibra do algodão: finura ( $\mu$ g), resistência (gf tex ${ }^{-1}$ ), comprimento (mm 2,5\% S.L.), uniformidade de comprimento (\%), índice de fibra curta (\%), elongação (\%), fiabilidade, reflectância (\%) e grau de amarelo

\begin{tabular}{|c|c|c|c|c|c|c|c|c|c|}
\hline \multirow{2}{*}{$\begin{array}{l}\text { Tratamento } \\
\left(\mathbf{k g ~ N ~ h a}^{-1}\right)\end{array}$} & \multicolumn{9}{|c|}{ V A R IÁ V E IS } \\
\hline & Finura & Resistência & Comprim. & U. Compr. & IFC & Elongação & Fiabilidade & Reflectância & G. amarelo \\
\hline $\mathrm{T}_{1}(0)$ & - & - & - & - & - & - & - & - & - \\
\hline $\mathrm{T}_{2}(60)$ & 4,15 & 25,35 & 28,70 & 82,80 & 8,10 & 10,90 & 1861,00 & 57,05 & 9,40 \\
\hline $\mathrm{T}_{3}(100)$ & 3,56 & 29,30 & 29,88 & 85,28 & 4,90 & 9,74 & 2267,40 & 72,62 & 9,10 \\
\hline $\mathrm{T}_{4}(200)$ & 3,48 & 29,26 & 29,88 & 85,18 & 5,00 & 10,48 & 2300,20 & 74,52 & 9,20 \\
\hline $\mathrm{T}_{5}(250)$ & 3,64 & 29,96 & 29,96 & 85,46 & 3,96 & 9,96 & 2346,20 & 75,98 & 8,87 \\
\hline $\mathrm{T}_{6}(300)$ & 3,68 & 30,04 & 30,34 & 85,76 & 4,05 & 10,14 & 2319,40 & 75,36 & 9,20 \\
\hline Média & 3,70 & 28,77 & 29,74 & 84,90 & 5,20 & 10,23 & 2218,84 & 71,10 & 9,14 \\
\hline BRS1878H & 4,5 & 20,8 & 28,0 & 50,5 & & 7,0 & & 61,0 & 9,9 \\
\hline
\end{tabular}


Tabela 6. Resumo das análises de variância e de regressão das variáveis da qualidade física de fibra do algodão. EMBRAPA Algodão, Campina Grande, PB

\begin{tabular}{|c|c|c|c|c|c|c|c|c|c|c|}
\hline \multirow{2}{*}{ F.V. } & \multirow{2}{*}{ G.L. } & \multicolumn{9}{|c|}{ QUADRADO MÉDIO } \\
\hline & & Finura & Resist. & Comp. & U. Compr. & IFC & Elong. & Fiabilid. & Reflect. & G. amar. \\
\hline Blocos & 4 & $0,77 \mathrm{~ns}$ & $22,14 \mathrm{~ns}$ & $48,20 \mathrm{~ns}$ & $322,30 \mathrm{~ns}$ & $4,41 \mathrm{~ns}$ & $6,79 \mathrm{~ns}$ & $191.071,5 \mathrm{~ns}$ & $183,50 \mathrm{~ns}$ & $5,42 \mathrm{~ns}$ \\
\hline Tratamentos & 5 & $11,56^{\star *}$ & 855,28 ** & $859,65^{\star *}$ & $6.870,00 * *$ & $13,41^{* *}$ & 93,00 ** & $5.278,34^{* *}$ & $5.594,12^{\star *}$ & $76,12^{\star \star}$ \\
\hline Linear & 1 & 42,04 ** & $3.141,61$ ** & $3.107,54$ ** & $24.499,83^{* *}$ & 35,90 ** & $332,62^{\star *}$ & $19.293,99 * *$ & $20.688,41 * \star$ & $267,17^{\text {** }}$ \\
\hline Quadrática & 1 & $13,50^{* *}$ & 911,40 ** & $994,52^{\star *}$ & $8.219,44^{* *}$ & $28,81^{* *}$ & $117,86^{* *}$ & $5.674,74^{* *}$ & $5.740,92^{* *}$ & $94,00^{* \star}$ \\
\hline Polin. $3^{\circ}$ Grau & 1 & $0,66 \mathrm{~ns}$ & $3,50 \mathrm{~ns}$ & $10,00 \mathrm{~ns}$ & $110,11 \mathrm{~ns}$ & $2,31 \mathrm{~ns}$ & 2,03ns & $1.780,84 \mathrm{~ns}$ & $0,24 \mathrm{~ns}$ & $3,04 \mathrm{~ns}$ \\
\hline Polin. $4^{\circ}$ Grau & 1 & $0,62 \mathrm{~ns}$ & $126,92 \mathrm{~ns}$ & $103,71 \mathrm{~ns}$ & $900,18 \mathrm{~ns}$ & $0,02 \mathrm{~ns}$ & $10,37 \mathrm{~ns}$ & $850824,30^{\star}$ & $957,87^{\star}$ & $11,95 \mathrm{~ns}$ \\
\hline Polin. $5^{\circ}$ Grau & 1 & $0,98 \mathrm{~ns}$ & $92,99 \mathrm{~ns}$ & $82,44 \mathrm{~ns}$ & $620,48 \mathrm{~ns}$ & $0,03 \mathrm{~ns}$ & $2,17 \mathrm{~ns}$ & $570.372,10 \mathrm{~ns}$ & 583,16 ns & $4,40 \mathrm{~ns}$ \\
\hline Resíduo & 20 & 0,927 & 39,00 & 43,35 & 348 & 2,66 & 6,24 & $188.085,20$ & 186,45 & 4,62 \\
\hline Total & 29 & & & & & & & & & \\
\hline CV & & 36,04 & 29,14 & 29,93 & 29,80 & 51,72 & 33,55 & 26,08 & 25,50 & 32,19 \\
\hline
\end{tabular}

ns - Valores estatisticamente não significativos

* - Valores estatisticamente significativos pelo teste $\mathrm{F}$ a nível de $5 \%$ de probabilidade

** - Valores estatisticamente significativos pelo teste $\mathrm{F}$ a nível de $1 \%$ de probabilidade

Com o resumo das análises de variância (Tabela 6) percebese a ocorrência de efeito significativo dos tratamentos pelo teste $\mathrm{F}$, a nível de $1 \%$ de probabilidade para todas as variáveis avaliadas. O desdobramento da regressão permite afirmar-se que todas as variáveis se ajustaram aos modelos linear e quadrático pelo teste $\mathrm{F}$, a nível de $1 \%$ de probabilidade , não havendo, portanto, efeitos significativos dos tratamentos para os demais modelos testados, com exceção da fiabilidade e reflectância da fibra, que, se ajustaram, também, ao modelo quártico pelo mesmo teste, mas a nível de 5\% de probabilidade. Embora ocorrendo efeitos linear e quadrático significativos dos tratamentos para todas as variáveis, optou-se pela regressão quadrática para expressar os resultados em virtude dos valores mais elevados dos coeficientes de determinação $\left(\mathrm{R}^{2}\right)$ observados.

As características físicas da fibra do algodão em função das doses de biossólido, estão representadas nas Figuras 1 a 3 . Analisando-as, verifica-se que as variáveis da qualidade física de fibra do algodão foram afetadas pelas doses de biossólido, uma vez que estas, de maneira geral, aumentaram, de acordo com a elevação das doses de biossólido; todavia, houve decréscimo dessas variáveis para as maiores doses empregadas, indicando que este nutriente deve ser aplicado em doses adequadas para melhor resposta do algodão. Neste sentido, estimou-se, através da derivada das equações de regressão, para as variáveis em que é de interesse a obtenção do valor máximo, tais como resistência, comprimento, uniformidade de comprimento, elongação, fiabilidade e reflectância, a dose de biossólido responsável pela obtenção desse valor (ponto de inflexão da curva), sendo de 292, 335, 237, 220, 225 e $231 \mathrm{~kg} \mathrm{~N} \mathrm{ha}^{-1}$, respectivamente. Esses resultados permitem afirmar que a região factível para essas variáveis está compreendida entre as doses de biossólido equivalentes a 220 e 335 kg N ha-1 . Excetuaram-se, nesta estimativa, as variáveis índice de fibra curta e grau de amarelo tendo em vista que, quanto menor for o valor dessas variáveis, melhor será, em termos de qualidade tecnológica da fibra do algodão.

Embora as doses de biossólido tenham exercido efeitos significativos sobre as variáveis elongação (Figura 2C) e grau de amarelo (Figura 3C) verifica-se que, em virtude dos baixos valores dos coeficientes de determinação $(0,21$ e 0,48 , respectivamente), as equações de regressão constantes nas referidas figuras exprimem, segundo Rodrigues (1993), a ausência de relação entre X e Y, isto é, entre as doses de biossólido e essas variáveis: um $\mathrm{R}^{2}=0,21$ significa que $21 \%$ da variância da elongação (Y) são atribuídos às doses de biossólido (X); isso, de acordo com este autor, eleva o que ele denominou de coeficiente de alienação (K), e tal coeficiente, que é função do coeficiente de correlação $\left\{K=\left(1-r^{2}\right)^{1 / 2}\right\}$, exprime a ausência de relação entre X e Y; portanto, pode-se dizer que há mais ausência de relação que de intensidade de relação entre as doses de biossólido, testadas neste experimento, e a elongação e o grau de amarelo das fibras.
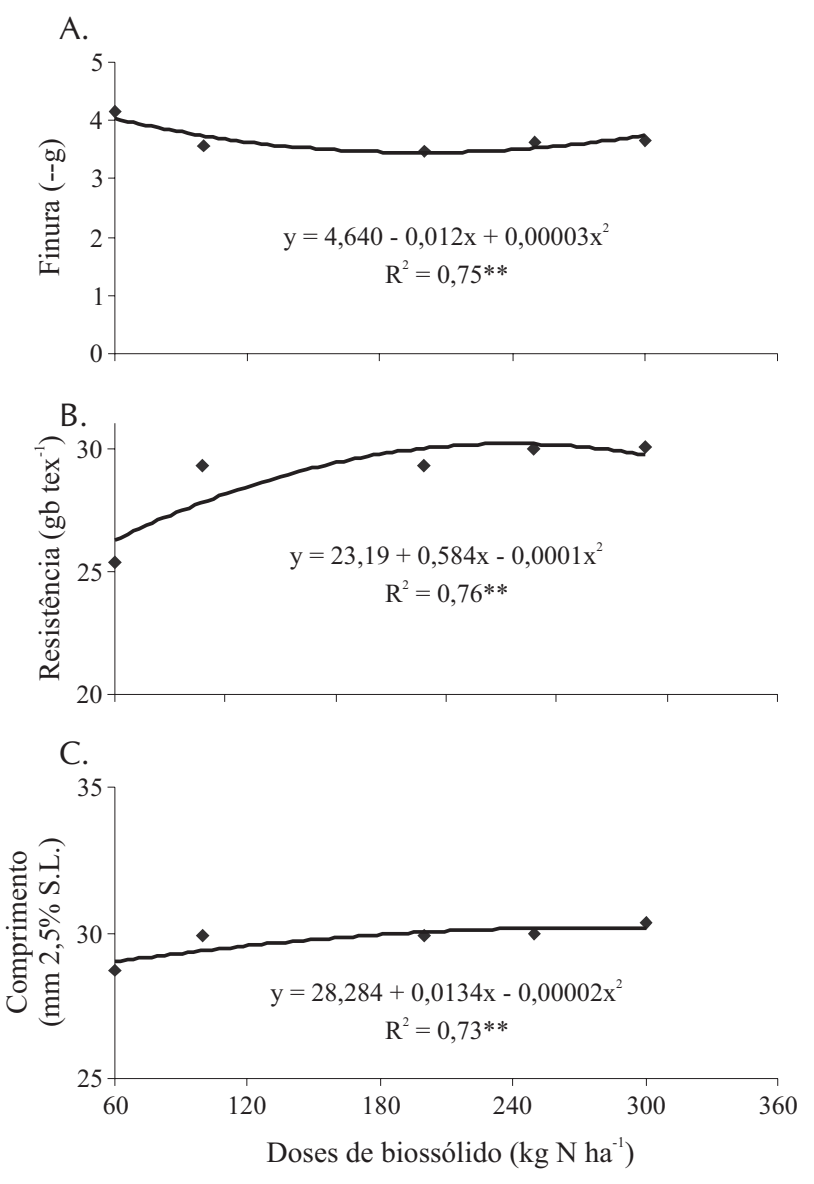

Figura 1. Finura $(A)$, resistência $(B)$ e comprimento $(C)$ de fibra do algodão em função das doses de biossólido 

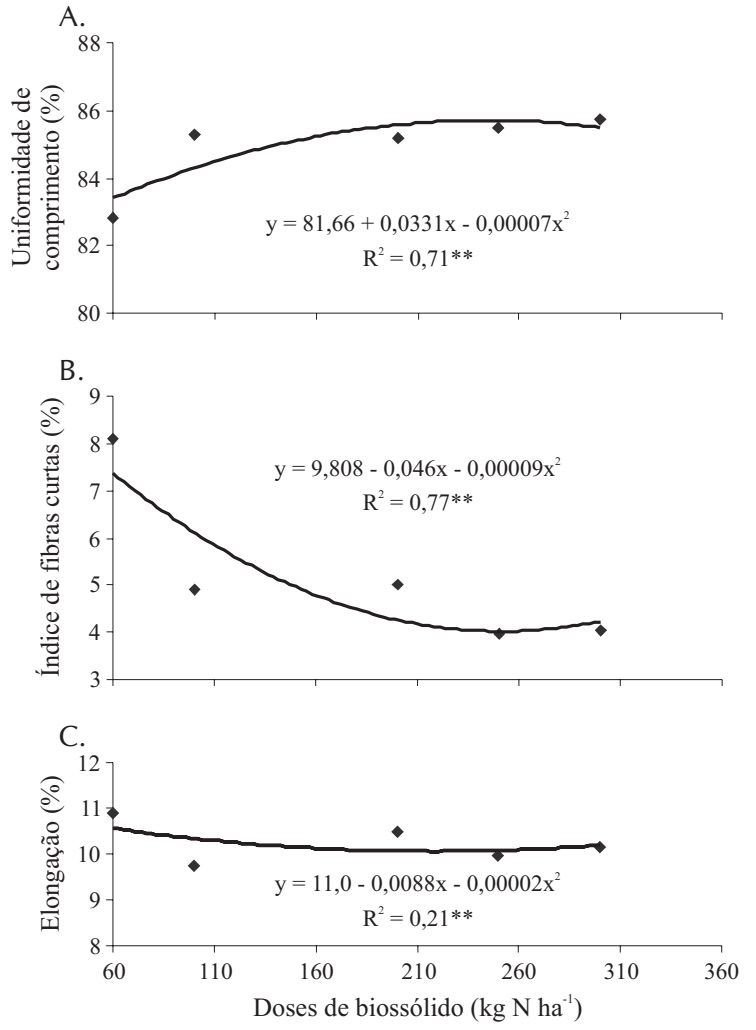

Figura 2. Uniformidade de comprimento (A), índice de fibra curta (B) e elongação $(\mathrm{C})$ de fibra do algodão em função das doses de biossólido

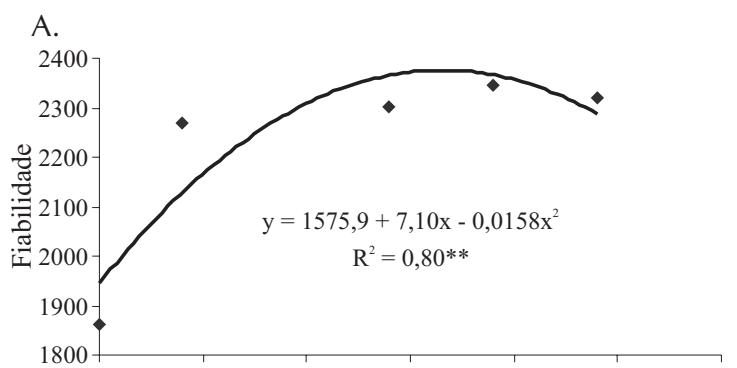

B.

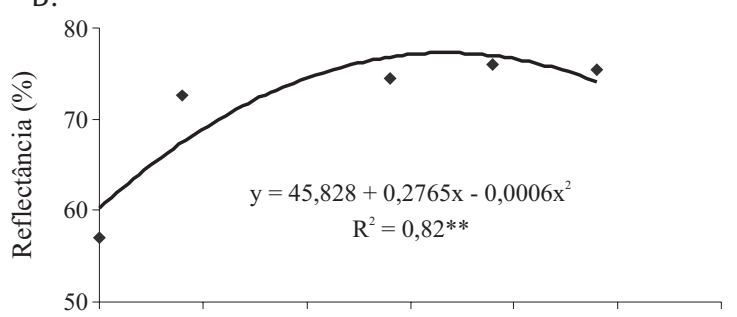

C.

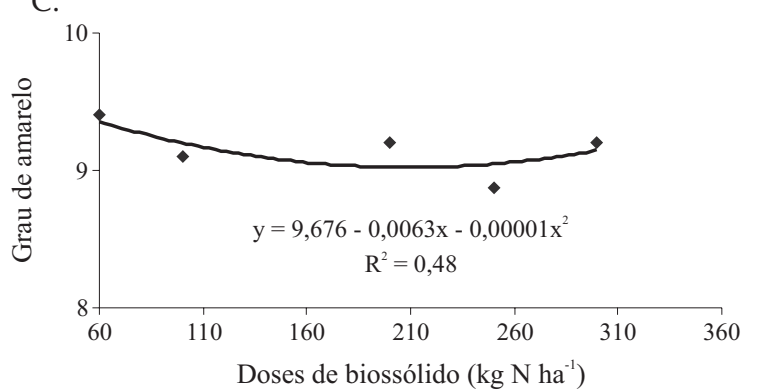

Figura 3. Fiabilidade (A), reflectância (A) e grau de amarelo (C) de fibra do algodão em função das doses de biossólido

\section{CONCLUSÕES}

1. As doses de biossólido exercem efeito significativo sobre as variáveis relacionadas à qualidade física de fibra de algodão herbáceo, com ajuste quadrático das respostas.

2. A variável finura foi classificada na categoria de fibra fina e o índice de fibras curtas o foi como baixo; no tocante ao grau de amarelo, o valor médio encontrado, está dentro da faixa comumente encontrada para a fibra do algodão.

3. A resistência, o comprimento, a uniformidade de comprimento, a elongação, a fiablilidade e a reflectância, foram classificadas como: média, longo, uniforme, muito alta, média e fibras claras, respectivamente.

4. A região factível para as variáveis relacionadas à qualidade tecnológica da pluma do algodoeiro herbáceo, variedade BRS 187 8H, situou-se entre as doses de biossólido equivalentes a 220 e $335 \mathrm{~kg} \mathrm{~N} \mathrm{ha}^{-1}$.

5. A dose de biossólido equivalente a $292 \mathrm{~kg} \mathrm{~N} \mathrm{ha}^{-1}$ foi a que proporcionou o valor máximo para a variável resistência de fibra, que é tomada como base de compra do algodão.

\section{AgRADECIMENTOS}

Os autores agradecem à FINEP, pelo apoio financeiro mediante o Programa de Pesquisa de Saneamento Básico (PROSAB) e ao Programa de Núcleo de Excelência (PRONEX).

\section{LITERATURA CITADA}

AWWA - American Water and Wastewater Association. Standard methods for the examination of water and wastewater. 18.6h. Denver, CO, 1992. 1092p

Andreoli, C. V.; Souza, M. L de P.; Comim, J. J.; Gioppo, P. J.; Castilho, D. S. B. Bases para uso do lodo de esgoto da ETEBelém. In.: Simpósio Luso-brasileiro de Engenharia Sanitária e Ambiental, 6, 1994, Florianópolis.Anais... Rio de Janeiro: ABES, 1994. p.389-419.

Bailenger, J. Mechanism of parasital concentration in coprology and their pratical consequences. Journal American Medicine Techology, v.1, n.4, p.65-71, 1979.

Berton, R. S.; Camargo, O. A.;Valadares, J. M. Absorção de nutrientes pelo milho em resposta à adição de lodo de esgoto a cinco solos paulistas. Revista Brasileira de Ciência do Solo, Campinas, v.13, n.2, p.187-192, 1989.

CNPA - Centro Nacional de Pesquisa do Algodão - EMBRAPA. BRS 187 8H: Nova cultivar de algodoeiro herbáceo para as condições do Nordeste. Campina Grande: EMBRAPA, 2000. Folder.

Dias, F. L. F. Efeito da aplicação de calcário, lodo de esgoto e vinhaça em solos cultivados com sorgo granífero (Sorghum bicolor L.). Jaboticabal: UNESP, 1994, 74p. Tese Doutorado

EMBRAPA - Empresa Brasileira de Pesquisa Agropecuária. Centro Nacional de Pesquisa do Solo. Sistema Brasileiro de Classificação do Solo. Rio de Janeiro: Embrapa CNPS, 1999. 412p. 
Gaspard, P. G.; Wiart, J.; Schwartbrod, J. A method for assessing the viability of nematode eggs in sludge. Environmental Technology, v.17, p.415-420, 1996.

Ilhenfeld, R. G. K.; Andreoli, C. V.; Lara, A. I. Higienização do lodo de esgoto. In: Uso e manejo de lodo de esgoto na agricultura. Rio de Janeiro: PROSAB, 1999. Cap4, p.744-752.

Neiva, M. R. Reciclagem agrícola de biossólidos da ETE Cetrel - uma experiência ambientalmente correta. In.: Congresso Brasileiro de Engenharia Sanitária e Ambiental, 20, 1999. Rio de Janeiro. Anais... Rio de Janeiro: ABES, 1999. p.479-477.

Oliveira, F. C. Disposição de lodo de esgoto e composto de lixo urbano num Latossolo Vermelho-Amarelo cultivado com cana-de-açúcar. Piracicaba: ESALQ/USP, 2000. 237p. Tese Doutorado

Rodrigues, P. C: Bioestatística. 2.ed. Niterói: RJ, EDUFF, 1993. 268p.

Ros, C. O.; Aita, C.; Cerettam, C. A.; Fries, M. R. Lodo de esgoto: Efeito imediato no milheto e residual na associação aveiaervilhaça. Revista Brasileira de Ciência do Solo, Campinas, v.17, p.257-261, 1991.
Santana, J. C. F. de; Wanderley, M. J. R. Interpretação de resultados de fibra, efetuadas pelo instrumento de alto volume (HVI) e pelo finurímetro-maturímetro $\left(\mathrm{FMT}_{2}\right)$. Embrapa/ CNPA. N. 41, p.1-9, 1995. Comunicado Técnico

Santana, J. C. da S. Características tecnológicas da fibra de duas cultivares de algodão armazenadas em dois municípios paraibanos. Campina Grande: UFCG, 2002. 48p. Dissertação Mestrado

Tsutiya, M. T. Tecnologias emergentes para a disposição final de biossólidos das estações de tratamento de esgotos. In: Congresso Brasileiro de Engenharia Sanitária e Ambiental, 20, 1999a, Rio de Janeiro. Anais... Rio de Janeiro: ABES, 1999a. p.762-770.

Tsutiya, M. T. Metais pesados: o principal fator limitante para o uso agrícola de biossólidos das estações de tratamento de esgotos. In: Congresso Brasileiro de Engenharia Sanitária e Ambiental, 20, 1999b, Rio de Janeiro. Anais... Rio de Janeiro: ABES, 1999b. p.753-761.

USEPA - United State Environmental Protection Agency. Control of pathogens and vector attraction in sewage sludge under 40 CFR part 503. Office of water, Office of science and technology sludge. Risk Assessment Branch. Washington, DC: editora: Federal Register, 20460, 1992. 147p 